\title{
АКТУАЛЬНЫЕ ПРОБЛЕМЫ ЗАКОНОДАТЕЛЬНОГО РЕГУЛИРОВАНИЯ КОНФЛИКТА ИНТЕРЕСОВ В СФЕРЕ ОБРАЗОВАНИЯ
}

В статье автором обозначены актуальные вопросы законодательного регулирования конфликта интересов в образовательной среде. Проведенный анализ норм права позволил обозначить особенности и основные проблемы регулирования подобных ситуаций.

В сфере образования, за долгие годы, сформироваласьодна изсамых «злокачественныхпроблем», которая является дестабилизирующим фактором в укреплении и развитии всей образовательной системы в целом коррупция.

Опыт борьбы Российской Федерации с коррупцией в сфере образования продемонстрировал необходимость комплексного подхода и принятия действенных мер, которые возможны лишь при наличии оптимального и системного антикоррупционного законодательства.

Автором выделены основные причины, порождающие коррупционные проявления в деятельности педагогических работников, а также приводится точка зрения о необходимости уточнения позиций, указанных в Ф3 «Об антикоррупционной деятельности», т.к. с правовой точки зрения, нормы указанного федерального закона регулируют правовое положение государственных и муниципальных служащих, однако применимы и к педагогическим работникам, несмотря на то, что они не имеют соответствующий статус.

На основании проанализированных фактов, автором обосновывается необходимость закрепления на законодательном уровне Перечня ситуаций, при которых становится явным конфликт интересов, что позволит урегулировать проблему правильной квалификации ситуации конфликта интересов педагогических работников.

Выявлено, что правовая регламентация ситуации «конфликт интересов педагогического работника» требует поправок на законодательном уровне. Установлена необходимость обязательности регулирования данной ситуации локальными актами образовательных организаций.

Ключевые слова: образование, конфликт интересов, конфликт интересов педагогического работника, регулирование споров между участниками образовательных отношений.

\section{O. A. Provodina}

\section{TOPICAL PROBLEMS OF LEGAL REGULATION OF CONFLICT OF INTEREST IN EDUCATION}

The article specifies topical issues of legislative regulation of the conflict of interest in education. The analysis of the law allowed identifying the features and main problems of regulation in the given field.

One of the most "malignant problems", which is a destabilizing factor in the strengthening and development of the entire educational system as a whole - corruption - has formed in the educational environment over the last years.

The experience of the Russian Federation in the fight against corruption in the field of education has demonstrated the need for an integrated approach and effective measures that are possible only in the presence of optimal and systemic anti-corruption legislation.

The author highlights the main causes of corruption in the activities of the teaching staff, as well as the necessity to clarify the positions specified in the Federal law "On anti-corruption activities", because from a legal point of view, the rules of the Federal law regulate the legal status of state and municipal employees, but are applicable to the teaching staff, despite the fact that they do not have the appropriate status.

On the basis of the analyzed facts, the author substantiates the need to consolidate at the legislative level a list of situations in which a conflict of interest becomes apparent, which will resolve the problem of the correct qualification of the conflict of interest situation.

It is revealed that the legal regulation of the situation "conflict of interests of a member of the teaching staff" requires amendments at the legislative level. The necessity of mandatory regulation of this situation by local acts of educational organizations is established.

Key words: education, conflict of interest, conflict of interests of a member of the teaching staff, regulation of disputes between participants of the educational relations.

${ }^{1}$ Статья подготовлена и издана в рамках выполнения государственного задания Министерства образования и науки РФ № 29.12941.2018/12.1 «Исследование и информационно-аналитическое обеспечение процессов и мероприятий в рамках многостороннего и двустороннего сотрудничества в сфере науки, инноваций, образования и молодежной политики Российской Федерации со странами Кавказа, Южной Осетией и Абхазией» на 2018 год 
Система образования, как и вся специфика ее деятельности, в сущности подразумевает столкновение интересов участников образовательных отношений

В современных условиях развития ссреры образования, проблема разрешения конфликтов интересов педагогических работников приобретает все большую актуальность в образовательной деятельности.

Соблюдение нравственных и этических норм педагогическим работником, относится к его обязанностям, хотя специальной формализации эти нормы не имеют. В действительности, степень формализации требований к педагогическим работникам имеет достаточно невысокий показатель, в связи с чем нередко возникает вопрос, выходит ли за рамки нравственности и профессиональной этики конкретное поведение педагогического работника.

Ситуации, при которых возможно проследить конфлликт интересов педагогического работника, существовали задолго до принятия в 2012 г. Федерального закона N 273-Ф3 «Об образовании в Российской Федерации» (далее - Закон об образовании). Однако, как правовой институт сферы образовательной деятельности, с присущими ему юридическим признаками, начал функционировать лишь с принятием закона.

В Законе об образовании дано следующее определение понятия «конфликт интересов педагогического работника» - ситуация, при которой у педагогического работника при осуществлении им профессиональной деятельности возникает личная заинтересованность в получении материальной выгоды или иного преимущества и которая влияет или может повлиять на надлежащее исполнение педагогическим работником профессиональных обязанностей вследствие противоречия между его личной заинтересованностью и интересами обучающегося, родителей (законных представителей) несовершеннолетних обучающихся. Иными словами, конфликт интересов педагогического работника представляет собой заинтересованность педагогического работника в получении материальной выгоды при выполнении им своей профессиональной деятельности.

В частности, под данное определение подпадает норма ст. 48 Закона об образовании, которая определяет запрет на оказание платных образовательных услуг в конкретной организации, если это приводит к конфрликту интересов педагогического работника.

Исходя из определения, закрепленного в Законе об образовании, сущность конфликта интересов заключается в противопоставлении профессиональных обязанностей педагогического работника [1, p. 25] и личной заинтересованностью, т.е. при такой ситуации, когда в процессе осуществления трудовой деятельности у педагогического работника появляется возможность получить выгоду как материального, так и нематериального характера, взамен на выполнение (ненадлежащее выполнение) им своих профессиональных обязанностей.
Безусловно, подтекст данной нормы указывает на наиболее очевидный вид деятельности репетиторство, предполагая, что это может повлиять на отношения между обучающимся и преподавателем во время основного образовательного процесса. Ситуаций, при которых возможно наступление конфликта интересов, помимо репетиторства, может быть гораздо больше: от конкурсных жюри, до ситуаций, граничащих с коррупционной составляющей. При этом, фундаментом для образования подобного рода ситуаций выступают проблемы нравственно-этического и правового характера.

Под конструкции понятий «конфликт интересов» и “личная заинтересованность» подходит множество жизненных ситуаций. Наличие правовой неопределенности, безусловно, порождает большое количество злоупотреблений в данной сфере деятельности как со стороны органов, контролирующих данный процесс, так и со стороны самих контролируемых лиц.

В настоящее время, законодательно не определены правовые рамки данной категории, в связи с чем, конфликт интересов педагогического работника, как правовая норма, довольно сложна в правоприменении.

Во-первых, доказать сам факт ведения платной деятельности, крайне сложно, во-вторых, необходимо достоверно установить факт наличия конфликта интересов, в-третьих, перспективы привлечь педагогического работника к ответственности весьма неоднозначны.

Следует понимать, что, исходя из установленных в Законе об образовании норм, нет четкого запрета на оказание платных образовательных услуг в образовательных организациях, однако, при условии возможности возникновении конфрликта интересов - они (платные услуги) подлежит запрету.

В связи с этим, в научном мире возникает не мало дискуссий по этому вопросу. Ведь, юридически законодатель устанавливает возможность осуществления данной деятельности, но фактически определяет рамки, пределы которых формально не установлены.

Несмотря на то, что педагогические работники относятся к образовательной сфрере, не являются ни государственными, ни муниципальными служащими, в своей профессиональной деятельности они приближены к их статусу, что определяется критерием публичности их деятельности. Тем самым, в процессе осуществления профессиональных обязанностей и совершая юридически значимые действия, порождающие права и обязанности у других лиц, педагогические работники автоматически приравниваются к должностным лицам.

В Федеральном законе от 25.12.2008 № 273Ф3 «О противодействии коррупции» (далее - Закон об антикоррупционной деятельности) законодатель закрепляет понятие конфликта интересов и определяет это понятие как ситуацию, при которой личная заинтересованность (прямая или косвенная) лица, замещающего должность, за- 
мещение которой предусматривает обязанность принимать меры по предотвращению и урегулированию конфликта интересов, влияет или может повлиять на надлежащее, объективное и беспристрастное исполнение им должностных (служебных) обязанностей (осуществление полномочий)

Под личной заинтересованностью понимается возможность получения доходов в виде денег, иного имущества, в том числе имущественных прав, услуг имущественного характера, результатов выполненных работ или каких-либо выгод (преимуществ) [2].

Проблемы противодействия коррупции в ссрере образования долгое время остаются в поле внимания, как со стороны органов государственной власти, так и институтов гражданского общества и общественных организаций

Причин появления коррупции в сфере образования довольно много. К основным (по мнению автора) необходимо отнести следующие

1. Низкий уровень оплаты труда педагогических работников и низкий социальный статус

Ситуация в стране такова, что заработные платы учителей и преподавателей остаются одними из самых низких. Потребности педагогов в полной мере не реализовываются, что, как следствие, приводит к взяточничеству.

Низкое социальное положение педагогических работников в обществе привело к тому, что очень часто в образовательных организациях трудоустраиваются неквалифицированные кадры, что в безусловной мере влияет на процесс образования;

2. Ко второму пункту необходимо отнести недофинансирование системы образования. Именно эта причина приводит к тому, что повсеместно практикуется сбор денег с обучающихся и их родителей (законных представителей) на содержание благосостояния учебного заведения, что противоречит основным конституционным нормам, согласно которым, образование в Российской Федерации является бесплатным;

3. Низкая правовая культура обучающегося состава о значимости образования в современном мире, что характеризуется падением нравственности в обществе в целом (в большей степени касается студентов высших учебных заведений);

4. Отсутствие стимулирования педагогических работников через установленную систему поощрений. Данная причина взаимосвязана с низкой заработной платой педагогических работников. Именно этот критерий может являться стимулом совершенствования педагогической деятельности, повышения уровня нравственности и гражданской ответственности.

Анализируя причины проявления коррупции в образовательной среде, становится очевидно, что коррупция - это социальное явление и, к сожалению, в современной России это одна из серьезных угроз образовательной сферы.

В последние годы органами государственной власти был сформирован и реализован комплекс мер, направленных на предупреждение и преодоление коррупции в образовательной сфрере.
В числе таких мер следует назвать создание механизма предупреждения конфликта интересов педагогического работника.

Этот интерес обусловлен необходимостью консолидации усилий государственных и муниципальных служащих, должностных лиц, работников организаций, осуществляющих образовательную деятельность, а также самих обучающихся и их законных представителей.

Представляется безусловным, что повышение эфффективности деятельности по предупреждению и пресечению коррупционных проявлений в образовательной среде требует как общих правовых средств, закрепленных Законом об антикоррупционной деятельности, так и использования специальных механизмов, позволяющих учесть специфику регулируемых отношений [3, р. 124]. Таким инструментом и выступает Закон об образовании.

Однако следует учитывать, что закрепление термина «конфликт интересов" в Законе об антикоррупционной деятельности требует уточнений, т.к. в настоящее время указанный федеральный закон направлен исключительно на определенный круг субъектов - государственных и муниципальных служащих.

Таким образом, видна следующая картина: нормативное закрепление понятия «конфликт интересов» и «конфликт интересов педагогического работника" есть, а вот непосредственно сам порядок поведения педагогического работника при наступлении конкретной ситуации, и порядок регулирования конкретных ситуаций, подпадающих под понятие конфликта интересов педагогического работника - отсутствует

В свою очередь, ст. 45 Закона об образовании предусматривает право на защиту прав обучающихся, родителей (законных представителей) несовершеннолетних обучающихся, выражавшееся в возможности обращаться в комиссию по урегулированию споров между участниками образовательных отношений, в том числе по вопросам о наличии или об отсутствии конфликта интересов педагогического работника. При этом регулирование процесса функционирования данной комиссии отнесено к исключительной компетенции самих образовательных организаций. Так, некоторыми организациями, осуществляющими образовательную деятельность, принимаются специальные локальные акты, в которых оговорены случаи возникновения конфликта интересов педагогических работников, а также определен круг субъектов, кто может быть включен в указанную комиссию и определены основные задачи, функции и компетенция комиссии. Таким образом, говоря о локальном регулировании данного процесса, представляется, что принятие подобного нормативного акта остается на усмотрении руководителя образовательной организации, и не является обязательным.

Хочется также отметить, что одним из основных вопросов, которые ставятся на рассмотрение комиссии - вопрос о непосредственном моменте 
возникновения конфликта интересов педагогического работника. Именно этот факт представляет наибольшую значимость при рассмотрении конкретного дела. Ведь учитывая порядок деятельности указанной комиссии, выполнять свои функции она начинает лишь после непосредственного обращения обучающегося, либо его родителя (законного представителя), т.е. непосредственно тогда, когда уже произошел конфрликт интересов. Тем самым правовой регулятор начинает действовать на устранение уже возникшего конфликта, но не на его предупреждение.

Более того, анализ локальных актов, принятых в рамках исполнения законодательства в сорере образования, указывает на ряд проблем. В частности, это и применение формального подхода к подготовке локального акта, определяющего статус комиссий, и само фактическое закрепление порядка функционирования данных комиссий. По представлению законодателя формирование состава комиссии ориентируется на паритетных началах, однако на практике нормы о представительстве нередко нарушаются.

Таким образом, исходя из сложившейся практики, организации, осуществляющие образовательную деятельность, зачастую формально относятся к выполнению требований Федерального закона №273-Ф3 по разработке и принятию локального акта, регламентирующего вопросы создания и функционирования комиссий по урегулированию споров между участниками образовательных отношений

Представляется, что рассмотрение конкретной ситуации конфликта интересов педагогического работника осуществляется преимущественно на субъективной оценке межличностных отношений, изначально предполагающих готовность к взаимодействию. При этом можно уследить нарушение принципа независимости при принятии решений. В частности, посредством субъективного восприятия делается вывод о наличии личной заинтересованности в получении материальной выгоды или иного преимущества, а также о влиянии (в том числе потенциальном) на надлежащее исполнение педагогическим работником профессиональных обязанностей. Даже запрет на осуществление индивидуальной педагогической деятельности не является безусловным: оказание платных образовательных услуг должно вести к конфликту интересов, что, опять же, оценивается субъективно.

По этой причине, должен быть предусмотрен специальный механизм реагирования на подобные ситуации, что позволит в большей степени избежать декларативности, и повысить эффективность деятельности по предупреждению кон- фликта интересов педагогического работника

Говоря о локальном регулировании, хочется отметить безусловную необходимость и целесообразность их принятия и применения, как регулятора общественных отношений, однако отсутствие внешней правовой экспертизы, а также учитывая возможность недостаточной квалификации лиц, осуществляющих разработку локального акта [3, p. 126], может привести к существенному снижению эффективности регулирующего воздействия, одновременно повышая коррупционные риски

Следует учесть, что вопросы предупреждения и преодоления конфоликта интересов в образовательной сфере определены фрагментально и требуют более тщательной разработки.

Таким образом, автором обоснована необходимость закрепления на законодательном уровне перечня ситуаций, в которых может быть усмотрен конфликт интересов. Помимо установления Перечня, со стороны органов государственной власти требуется непосредственное участие в составлении методического пособия, которые определяло бы порядок урегулирования конфликта интересов педагогического работника.

Стоит отметить, что до настоящего времени не выработан и оперативный механизм противодействия коррупции в сорере образования, что обусловлено отсутствием должным образом согласованного законодательства.

Комиссии по урегулированию конфликта интересов в образовательных организациях могут стать эфффективным механизмом по разрешению спорных ситуаций, однако их правовой статус и порядок функционирования необходимо тщательно прописать, а именно эффективно раскрыть в подзаконных актах и рекомендациях органов государственной власти, уполномоченных в сфере образования, что, безусловно, позволит избежать декларативности и повысить эффективность деятельности по предупреждению конфликта интересов педагогического работника.

Также, необходимо исключить формальность по разработке локальных актов, регламентирующих вопросы по созданию и урегулированию споров между участниками образовательных отношений и их функционированию со стороны образовательных организаций, что в свою очередь будет способствовать предотвращению и комплексному регулированию конфрликта интересов, ограничив при этом частные интересы и личную заинтересованность работников на реализуемые ими трудовые функции, что безусловно окажет положительное влияние в целом на сферу образования.

\section{Литература}

1. Еремина Т.И. Правовое регулирование конфликта интересов в сфере образования // Практика правоприменения образовательного законодательства в профессиональных образовательных организациях в свете реализации федерального закона «Об образовании в Российской Федерации» // Материалы городской научно-практической конференции (Москва, 20 мая 2015). М.: ГБОУ ВО МГПУ, 2015. С.24 - 27.

2. Обзор практики применения судами в 2014 - 2016 годах законодательства Российской Федерации при рассмо- 
трении споров, связанных с наложением дисциплинарных взысканий за несоблюдение требований законодательства о противодействии коррупции (утв. Президиумом Верховного Суда РФ 30 ноября 2016 года) // Информационно-правовой портал «Гарант.ру».

3. Плюгина И. В. Правовые механизмы предупреждения коррупции в сфере образования // Журнал российского права. 2016. №12. С. 123-133.

4. Об образовании в Российской Федерации: федеральный закон от 29.12.2012 № 273-Ф3 (ред. от 03.08.2018) // Собрание законодательства РФ. 2012 . №53 (Ч. 1). Ст. 7598.

\section{References}

1. Eremina T. I. Pravovoe regulirovanie konflikta interesov v sfere obrazovaniya (Legal Regulation of Conflict of Interest in the Field of Education) // Praktika pravoprimeneniya obrazovatel'nogo zakonodatel'stva v professional'nyh obrazovatel'nyh organizaciyah v svete realizacii federal'nogo zakona «Ob obrazovanii v Rossijskoj Federacii»). Materialy gorodskoj nauchnoprakticheskoj konferencii (Moskva, 20 maya 2015). Moscow: MSPU publ., 2015. P. 24-27. (In Russian).

2. Obzor praktiki primeneniya sudami v 2014-2016 godah zakonodatel'stva Rossijskoj Federacii pri rassmotrenii sporov svyazannyh s nalozheniem disciplinarnyh vzyskanij za nesoblyudenie trebovanij zakonodatel'stva o protivodejstvii korrupcii (utv. Prezidiumom Verhovnogo Suda RF 30 noyabrya 2016 goda) (Review of the Practice of Application by the Courts in 2014-2016 of the Legislation of the Russian Federation in the Consideration of Disputes Related to the Imposition of Disciplinary Penalties for Non-Compliance with the Requirements of Anti-Corruption Legislation (Approved by the Presidium of the Supreme Court of the Russian Federation on November 30, 2016) // Informacionno-pravovoj portal «Garant.ru». (In Russian).

3. Plyugina I. V. Pravovye mekhanizmy preduprezhdeniya korrupcii v sfere obrazovaniya (Legal Mechanisms to Prevent Corruption in Education) // ZHurnal rossijskogo prava. 2016. No.2. P. 123-133. (In Russian)

4. Ob obrazovanii v Rossijskoj Federacii: federal'nyj zakon ot 29.12.2012 № 273-FZ (red. ot 03.08.2018) (On Education in the Russian Federation: Federal Law of 12/29/2012 No. 273-FZ (Revised from 08.08.2018) // Sobranie zakonodatel'stva Russian Federation. 2012. No. 53 (Part. 1). Art. 7598. (In Russian). 